\title{
Research on Prediction Method of Performance Degradation of Flexible Optoelectronic Film Material Processing Equipment Based on Adaptive Fuzzy Clustering
}

\author{
Yaohua Deng $\mathbb{D},{ }^{1,2}$ Kexing Yao $\mathbb{D}^{1},{ }^{1}$ and Qiwen $\mathrm{Lu} \mathbb{D}^{2}$ \\ ${ }^{1}$ School of Electro-Mechanical Engineering, Guangdong University of Technology, Guangzhou, Guangdong, China \\ ${ }^{2}$ Foshan Shike Intelligent Technology Co., Ltd., Foshan 528000, China \\ Correspondence should be addressed to Kexing Yao; yaokexing1018@qq.com and Qiwen Lu; 24084480@qq.com
}

Received 15 August 2018; Accepted 22 October 2018; Published 22 November 2018

Academic Editor: Nazrul Islam

Copyright (C) 2018 Yaohua Deng et al. This is an open access article distributed under the Creative Commons Attribution License, which permits unrestricted use, distribution, and reproduction in any medium, provided the original work is properly cited.

\begin{abstract}
Flexible photoelectric film is an anisotropic material. The slight change of equipment performance during processing is prone to cause deformation of the material. Therefore, it is important to predict the degradation of processing equipment performance. Since the performance degradation of flexible photoelectric film material Roll-to-Roll (R2R) processing equipment is a nonlinear process, this paper introduces an adaptive fuzzy clustering method to construct a fuzzy membership function model for calculating the performance degradation index of R2R processing equipment and studies the parameter solving method such as the AFCM division of the roller vibration data, the category center value of the fuzzy membership function, and the input data division area width. Finally, the performance degradation index calculation algorithm is designed. The roller shaft accelerated life test was carried out using self-made equipment. The test data were 1000 sets. The results showed that the root mean square eigenvalues and the kurtosis eigenvalues of the roller vibration data are sensitive to the performance degradation. The equipment performance curve described by the first and second types of performance degradation indicators was very stable in the early stage. After the $800^{\text {th }}$ group, the curve continued to decrease, and the change was more severe, indicating that the performance degradation of the equipment is more serious. In the $980^{\text {th }}$ group, the longer-lasting roller shaft was damaged, and the performance index value was about zero, which proved the correctness of the performance degradation prediction method proposed in this paper in calculating the performance degradation value of the equipment.
\end{abstract}

\section{Introduction}

In recent years, breakthroughs have been made in the research of wearable sensors, OLEDs, and film solar cells using flexible photoelectric films as substrate materials, and the demand for industrialization and large-scale production has been put on the agenda. At present, the R2R method is widely used in the international manufacturing of the above materials. The research shows that the $\mathrm{R} 2 \mathrm{R}$ processing quality of the flexible photoelectric film material is mainly caused by the working performance of the device, and since the flexible photoelectric film (hereinafter referred to as flexible material) is an anisotropic material, the deformation is diverse and uncertain, small changes in the performance of the core equipment of manufacturing equipment can easily lead to wrinkles, interlayer slippage, or breakage in the material processing process, so it is important to predict the performance degradation of flexible material processing equipment [1]. Recently, research on prediction methods of equipment performance degradation has become a research hotspot. For example, Jay Lee combines SOM neural network with statistical pattern recognition (SPR) to propose a prediction method for online adaptive equipment performance degradation, which is verified in the health monitoring experiment of machine test bench [2]; Faisal studied the risk prediction method using self-organizing map in the risk prediction of system failure and applied the probability analysis to classify the risk characteristics of the system [3]. Reference [4] combined Stream of Variation (SOV) model 


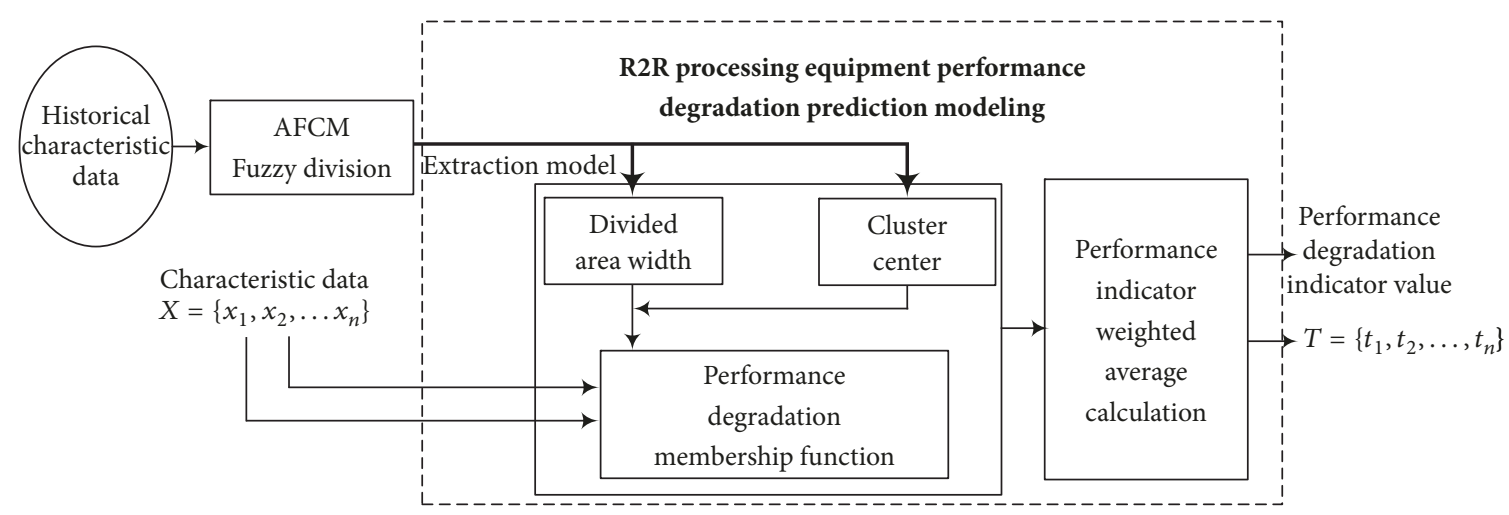

FIGURE 1: Modeling framework for performance deterioration prediction of R2R equipment based on AFCM.

with quality control chart for fault prediction of flexible material manufacturing systems.

Considering that the performance degradation of processing equipment of flexible photoelectric film materials is a nonlinear process in which the equipment gradually evolves from a normal state to a fault state, and the number of rollers of the flexible material R2R manufacturing equipment is large, and the movement of the roller shafts in the continuous manufacturing process is related to each other. The processing quality of flexible materials is affected by the performance status of many different types of roller shafts. In this paper, the vibration data of the $\mathrm{R} 2 \mathrm{R}$ processing roller shaft under normal conditions is used as the fuzzy prototype. Then the similarity relationship (fuzzy membership) between the fuzzy prototype and the latest collected roller vibration data is used to reflect the performance degradation of the roller. The large value of the fuzzy membership function indicates that the roller still works in the normal state. When the value is close to zero, the performance of the roller shaft is seriously degraded. The curve of the fuzzy membership function value reflects the performance degradation trend of the roller shaft. The following describes the construction of processing equipment performance prediction model based on adaptive fuzzy clustering, model parameter identification, and model verification.

\section{Flexible Material Processing \\ Equipment Performance Degradation Prediction Adaptive Fuzzy Clustering Modeling Framework}

As described above, the fuzzy membership relation (fuzzy similarity relationship) between the vibration data of the $\mathrm{R} 2 \mathrm{R}$ processing roller shaft under normal conditions and the most recently acquired roller shaft vibration data reflects the tendency of the roller shaft to deteriorate. Since the fuzzy membership function value indicates the similarity between a batch of vibration data and the fuzzy class prototype, if the value of the fuzzy membership function is close to 1 , it indicates that the performance state of the device is good. If the value of the fuzzy membership function is gradually reduced and close to 0 , it means that device performance is declining. Therefore, the derivative fuzzy membership function is the key link in the establishment of performance degradation prediction model [5]. Figure 1 shows the AFCMbased R2R device performance degradation prediction modeling framework. The Adaptive Fuzzy Clustering Method (AFCM) has the following advantages: it can adaptively adjust the initial cluster center, the radius of the segmentation area, and the number of cluster categories, and the division of the roller characteristic parameters can avoid the appearance of empty classes [6]. Therefore, the AFCM is used to fuzzy divide the data of the normal operation state of the equipment, and the fuzzy prototypes of various characteristic parameters of the roller shaft vibration data are obtained. Then, the clustering center $\mathrm{v}_{\mathrm{i}}$ of the characteristic parameters and the partitioning area width $\sigma_{\mathrm{j}}$ are solved, and the membership function of the device performance degradation is derived. Finally, the weighted average calculation of various performance indicators is used to obtain the calculation formula of equipment performance degradation index.

\section{Derivation of Calculation Model for Performance Degradation Index of Processing Equipment Based on AFCM}

3.1. AFCM Partition of Roller Shaft Vibration Data. In this paper, the adaptive fuzzy clustering method (AFCM) and the Mahalanobis distance are combined, and the Mahalanobis distance is used to represent the measurement of the distance of the roller vibration data of the processing equipment. The fuzzy partition matrix and the category center of characteristic parameter $\mathrm{x}_{\mathrm{t}}$ can be obtained by solving the minimum value of the objective function (formula (1)) of the c fuzzy partitions of the various parameters of the roller vibration data $[7,8]$.

$$
\min \{\mathrm{J}(\mathrm{X} ; \mathrm{U}, \mathrm{V})\}=\sum_{k=1}^{n} \sum_{t=1}^{C}\left(u_{t k}\right)^{m}\left(D_{t k M_{t}}\right)^{2}
$$

In formula (1), $\mathrm{X}=\left\{\mathrm{x}_{1}, \mathrm{x}_{2}, \cdots, \mathrm{x}_{\mathrm{n}}\right\}$ is the $\mathrm{n}$-dimensional input roller characteristic parameter set; $U=\left[\mathrm{u}_{t \mathrm{k}}\right]$ is the fuzzy division matrix of the input roller characteristic parameter set $\mathrm{X}\left(\mathrm{u}_{\mathrm{tk}}\right.$ is the $\mathrm{k}^{\mathrm{th}}$ characteristic parameter that belongs to the 
membership degree of the $\mathrm{t}^{\text {th }}$ class); $\mathrm{V}=\left\{\mathrm{v}_{1}, \mathrm{v}_{2}, \cdots, \mathrm{v}_{\mathrm{c}}\right\}$ is the cluster center set; $m \in[1,+\infty)$ is the cluster fuzzy weighted index (generally $m=2$ ); $D_{t k M_{t}}^{2}$ is the squared product norm of the data $x_{t}$ in the $n$-dimensional data space to the cluster center $\mathrm{v}_{\mathrm{t}}$ distance:

$$
D_{t k M_{t}}^{2}=\left\|x_{k}-v_{t}\right\|_{M_{t}}^{2}=\left(x_{k}-v_{t}\right)^{T} M_{t}\left(x_{k}-v_{i}\right)
$$

In formula (2), $\mathrm{M}_{\mathrm{t}}=\operatorname{det}\left(\mathrm{W}_{\mathrm{t}}\right)^{1 / \mathrm{n}} \cdot \mathrm{W}_{\mathrm{t}}^{-1}, \mathrm{~W}_{\mathrm{t}}$ is a positive definite symmetric matrix, and the adjustment of $\mathrm{W}_{t}$ is realized by the estimation of covariance (formula (3)). Thus, the division of the input roller characteristic parameter set is achieved.

$$
W_{t}=\frac{\left[\sum_{k=1}^{N}\left(u_{t k}\right)^{m}\left(x_{k}-v_{i}\right)\left(x_{k}-v_{t}\right)^{T}\right]}{\sum_{k=1}^{N}\left(u_{t k}\right)^{m}}
$$

The fuzzy partitioning of input data based on AFCM is mainly to solve the fuzzy partition matrix and cluster center. Formula (1) minimizes the objective function which is its fuzzy clustering basis, and there is $\sum_{i=1}^{c} u_{i k}=1$, $k=1,2, \ldots, N$, then formula (1) can be combined with the Lagrange multiplier method to integrate the objective function and constraints, and the Lagrange multiplier $\lambda$ is introduced to form a new objective function $[9,10]$.

$$
\begin{aligned}
\min \{\bar{J}(\mathrm{X} ; \mathrm{U}, \mathrm{V}, \lambda)\}= & \sum_{t=1}^{c} \sum_{k=1}^{N}\left(u_{t k}\right)^{m}\left(D_{t k M_{t}}\right)^{2} \\
& +\sum_{k=1}^{N} \lambda\left(\sum_{t=1}^{c} u_{t k}-1\right)
\end{aligned}
$$

The principle of AFCM division of the characteristic parameters of the roller shaft vibration data is to find the best $(\mathrm{U}, \mathrm{V}, \lambda)$ combination, so that the $\overline{\mathrm{J}}(\mathrm{X} ; \mathrm{U}, \mathrm{V}, \lambda)$ under the constraint condition, the characteristic parameters division of various roller shafts can reach a minimum value. Under the condition that formula (5) is satisfied, in the process of solving the minimum value of the objective function $\overline{\mathrm{J}}(\mathrm{X} ; \mathrm{U}, \mathrm{V}, \lambda)$, the optimization necessary condition of formula (4) needs to satisfy the requirements given by formula (6).

$$
\begin{aligned}
\sum_{t=1}^{c} u_{t k} & =1, \quad u_{t k} \in[0,1] \\
\frac{\partial \bar{J}}{\partial v_{t}} & =\sum_{k=1}^{N}\left(u_{t k}\right)^{m} \frac{\partial}{\partial v_{t}}\left[\left(x_{k}-v_{t}\right)^{T} M_{t}\left(x_{k}-v_{t}\right)\right]=0 \\
\frac{\partial \bar{J}}{\partial \mu_{t}} & =\left[m\left(u_{t k}\right)^{m-1}\left(D_{t k M_{t}}\right)^{2}+\lambda\right]=0 \\
\frac{\partial \bar{J}}{\partial \lambda} & =\sum_{k=1}^{N}\left(u_{t k}-1\right)=0, \quad 1 \leq i \leq c, 1 \leq t \leq N
\end{aligned}
$$
(hereinafter referred to as set 1), and the other type is the membership calculation result obtained by using the kurtosis as the characteristic value as input (hereinafter referred to as set 2). Adding the values of each individual item included in 
set 1 and then averaging, obtaining the first type of performance degradation index value of the processing equipment, adding the values of each single item included in set 2 , and then averaging, obtaining the second type of performance degradation index value of the processing equipment. Use the first and second types of performance degradation indicators to capture device performance degradation [11].

Assuming that the input characteristic parameter fuzzy partition matrix is $\mathrm{U}=\left[\mathrm{u}_{\mathrm{tk}}\right]$ after the AFCM division characteristic, and the c-group fuzzy category number is $\mathrm{R}_{\mathrm{t}}(1 \leq \mathrm{t} \leq \mathrm{c})$, then the category center $\mathrm{v}_{\mathrm{tq}}$ and corresponding variance $\sigma_{\mathrm{tq}}^{2}$ of $\mathrm{R}_{\mathrm{t}}$ are

$$
\begin{aligned}
& v_{t \mathrm{q}}=\left[\sum_{k=1}^{N}\left(u_{t k}\right)^{m}\right]^{-1} \cdot \sum_{k=1}^{N}\left(u_{t k}\right)^{m} x_{k} \\
& \sigma_{t q}^{2}=\sum_{k=1}^{N}\left(u_{t k}\right)^{\beta}\left(q_{k}-v_{t q}\right)^{2} \cdot\left[\sum_{k=1}^{N}\left(u_{t k}\right)^{\beta}\right]^{-1}
\end{aligned}
$$

$$
\mathrm{t}=1,2, \cdots, \mathrm{c}
$$

In the above formula, $v_{t q}$ is the category center value; $\sigma_{\mathrm{tq}}^{2}$ is the input data partition region width; $\mathrm{u}_{\mathrm{tk}}^{\mathrm{m}}$ is the $\mathrm{k}^{\text {th }}$ sample; $\mathrm{x}_{\mathrm{k}}$ belongs to the $\mathrm{t}^{\text {th }}$ membership value; $\mathrm{m}$ is the fuzzy degree introduced by the fuzzy clustering algorithm; $\mathrm{q}_{\mathrm{k}}$ is category value [12]. After AFCM clustering, the membership function of the corresponding characteristic parameter $\mathrm{x}_{\mathrm{k}}$ to $\mathrm{R}_{\mathrm{t}}$ is $\mu\left(\mathrm{x}_{\mathrm{k}}\right)$, then $\mu\left(\mathrm{x}_{\mathrm{k}}\right)$ can be expressed as follows [13]:

$$
\mu_{j t}\left(x_{k}\right)=e^{\left(x_{\mathrm{kj}}-\mathrm{v}_{\mathrm{tq}}\right)^{2} / \sigma_{t q}^{2}}, \quad \mathrm{t}=1,2, \cdots, \mathrm{c} ; \mathrm{j}=1,2, \cdots, \mathrm{n}
$$

where $\sigma_{\mathrm{tq}}$ is the divided region radius of the input characteristic parameter and $v_{t q}$ is the cluster center value of the $t^{\text {th }}$ cluster center. The physical meaning of the membership function $\mu_{\mathrm{jt}}\left(\mathrm{x}_{\mathrm{k}}\right)$ is to reflect the similarity relationship between the input characteristic parameter $\mathrm{x}_{\mathrm{k}}$ and the fuzzy class $R_{t}$ prototype. If the characteristic parameter $x_{k}$ is close to the fuzzy class prototype, the membership function $\mu_{\mathrm{jt}}\left(\mathrm{x}_{\mathrm{k}}\right)$ is close to 1 ; if the characteristic parameter $\mathrm{x}_{\mathrm{k}}$ is far from the fuzzy class prototype, the membership function $\mu_{\mathrm{jt}}\left(\mathrm{x}_{\mathrm{k}}\right)$ is close to 0 [14]. $\sigma_{\mathrm{tq}}^{2}$ reflects the quality of fuzzy partitioning. When the value of $\sigma_{\mathrm{tq}}^{2}$ is larger, the quality of AFCM partitioning is relatively poor. When the value of the variance $\sigma_{\mathrm{tq}}^{2}$ of all the fuzzy division categories is smaller, it is considered that the fuzzy division has a better result.

The performance degradation of the flexible material R2R processing equipment is mainly caused by the performance variation of each roller shaft, and the roller shaft performance degradation is a gradual process of random nonlinearization from the normal state to the fault state. From the perspective of membership degree, it is a continuous change process from 0 to 1 or from 1 to 0 . The degree of degradation of the roller performance can be evaluated by the value of the fuzzy membership function value given by formula (9). When the function value is close to 1 , it indicates that the roller performance is in a normal state. When the value of the membership function is close to 0 , it indicates that the performance of the roller shaft is seriously degraded.

\section{Model Verification and Test Experiment}

To verify the performance degradation index calculation model proposed above, the flexible photoelectric film material $\mathrm{R} 2 \mathrm{R}$ processing test was carried out using the experimental equipment of [4] (Figure 3). The roller shaft of the experimental equipment is mounted on the bearing housing. The roller shaft rotates during the machining process. Since the roller shaft and the bearing are connected together, the vibration speed of the roller shaft is reflected on the bearing. Therefore, a high-sensitivity triaxial acceleration vibration sensor is installed directly above the bearing housings of the unwinding roller shaft, the guide roller shaft, the driving roller shaft, and the winding roller shaft, to collect the vibration data of the roller during the processing of the equipment (the test device is shown in Figure 3).

The vibration sensor is installed on the bearing housing of each type of roller shaft, the processing speed of the equipment is set to $10 \mathrm{~m} / \mathrm{min}$, and all the bearings are forcibly lubricated. After being measured by standard instruments, the vibration frequency range of the roller shaft under normal running conditions is $10 \mathrm{~Hz}<\mathrm{f}<1000 \mathrm{~Hz}$. According to the expert's experience, the vibration velocity is used to evaluate the vibration of the roller shaft, and the 1000 sets of vibration characteristic data of the unwinding roller shaft, the guide roller shaft, the driving roller shaft, and the winding roller shaft are, respectively, collected, wherein the first 600 sets of data are collected under normal operating conditions of the equipment, and the next 400 sets of data are collected while reducing the lubrication of the roller shaft.

4.1. Characteristic Extraction of Vibration Data. Extracting time domain eigenvalues of the collected vibration data after noise reduction processing and taking the drive roller shaft as an example, Figure 4 is a curve graph of peak eigenvalues of vibration data, Figure 5 is a curve of eigenvalues of square root amplitude, Figure 6 is a curve of variance eigenvalues, Figure 7 is a graph of standard deviation eigenvalues, Figure 8 is a graph of eigenvalues of waveform indicators, Figure 9 is a graph showing the eigenvalue of the margin index, Figure 10 is a graph of the eigenvalue of the pulse index, Figure 11 is the root mean square (RMS) value curve, and Figure 12 is the kurtosis curve.

After comparing Figures 4, 5, 6, 7, 8, 9, 10, 11, and 12, it can be found that the RMS value curve and the kurtosis curve of the roller vibration data are very stable in the early stage. Until the end of life, there is a rapid rise phenomenon, which indicates that the RMS eigenvalues and the kurtosis eigenvalues are sensitive to the performance degradation of the roller shaft of flexible material R2R processing equipment.

4.2. Derivation Performance Degradation Index Calculation Membership Function. The characteristic parameters of the first 600 sets of data of each set of roller shaft vibration 

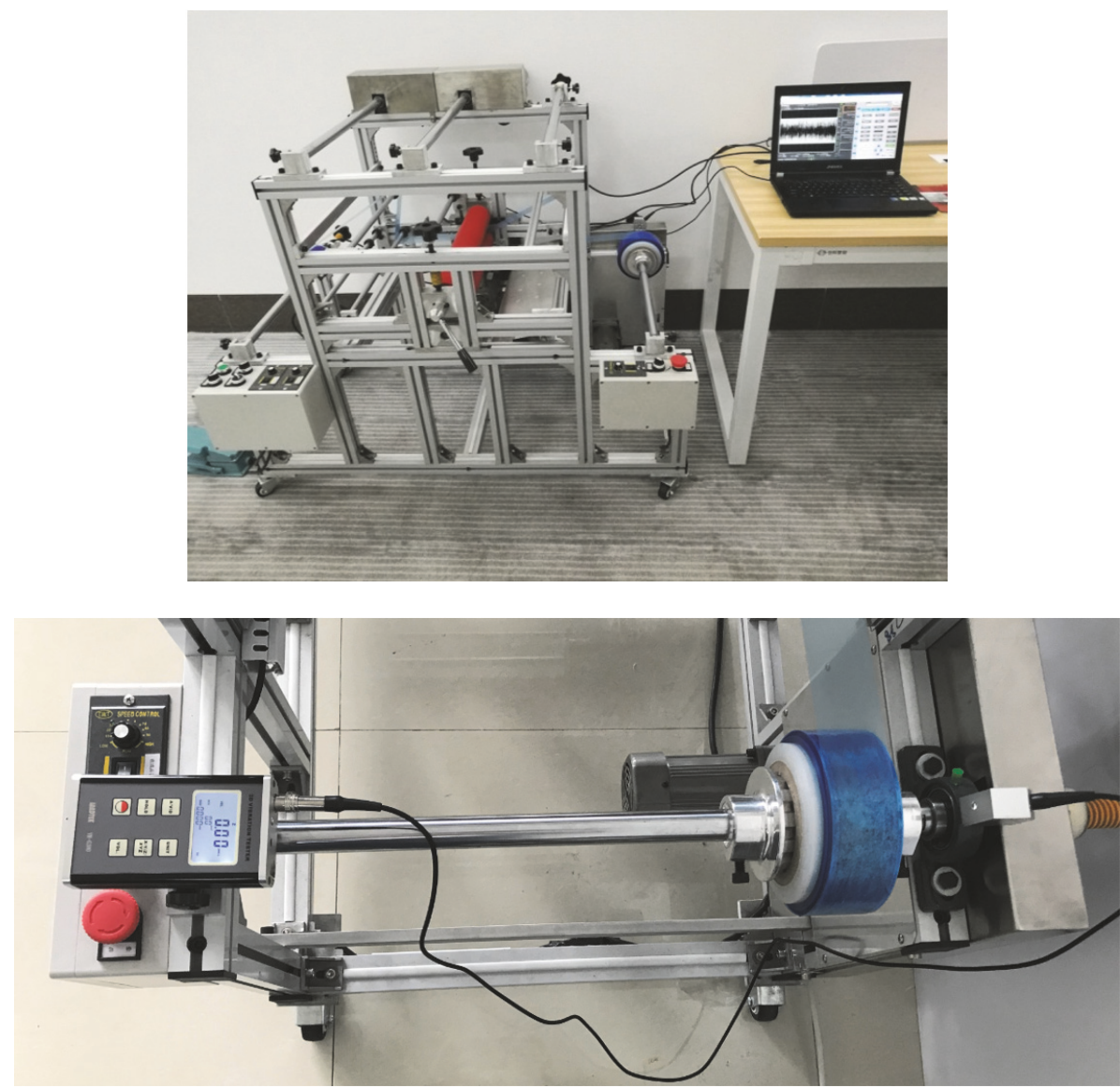

FIGURE 3: Roller shaft vibration test and roller shaft performance degradation test device.

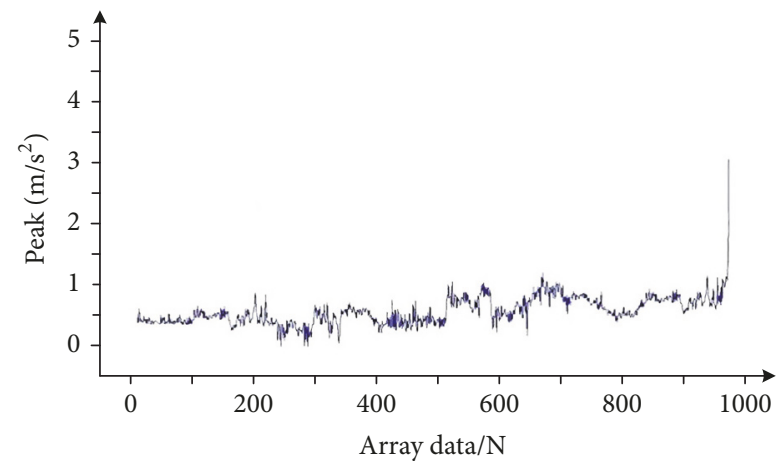

Figure 4: Peak.

data are normalized according to formula (10), and the normalized result of characteristic parameters shown in Table 1 is obtained (limited to the length, only 30 sets of data are listed).

$$
y=\frac{x-\text { MinValue }}{\text { MaxValue }- \text { MinValue }}
$$

where $\mathrm{x}$ is the time domain characteristic parameter and the result of $y$ normalization is $y \in[0,1]$.

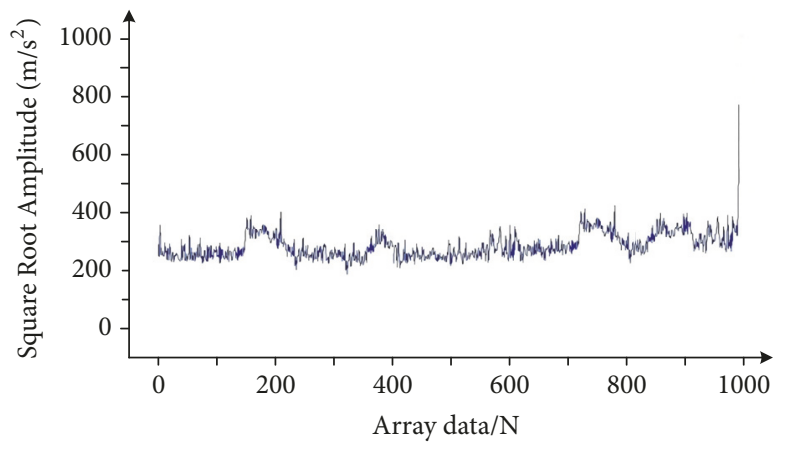

Figure 5: Square root amplitude.

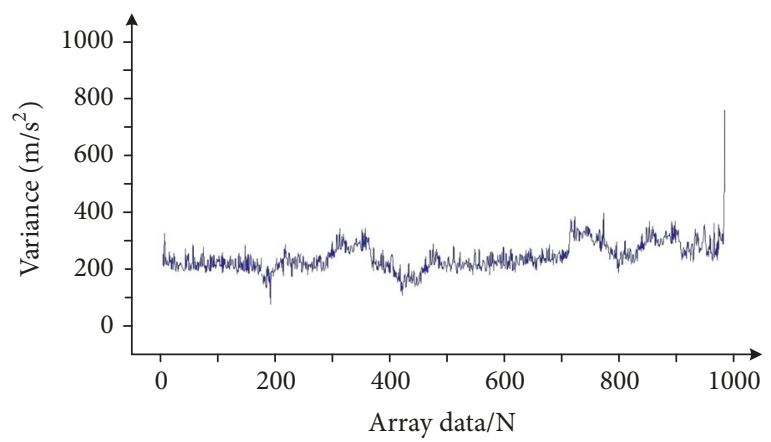

FIGURE 6: Variance. 


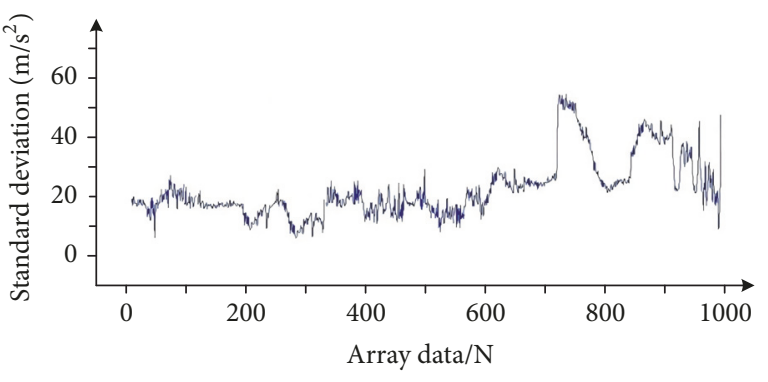

Figure 7: Standard deviation.

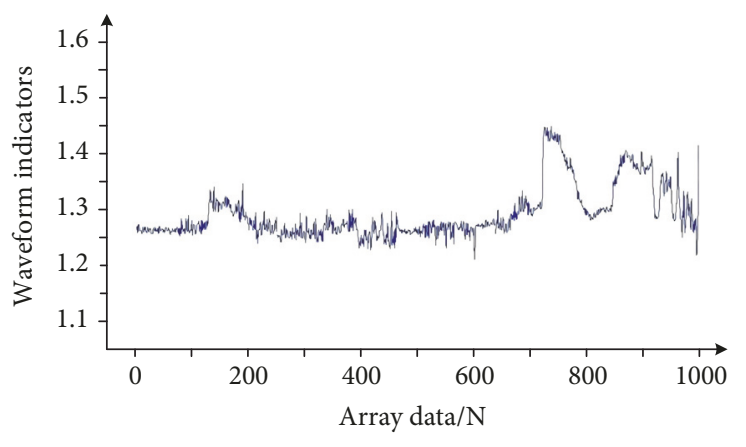

FIGURE 8: Waveform indicators.
According to formula (8), the category centers $\mathrm{v}_{\mathrm{i}}$, $\mathrm{i}=$ $1,2,3,4$ of the respective roller shaft vibration data and their corresponding divided region widths $\sigma_{\mathrm{iq}}^{2}$ are calculated as shown in Table 2.

By substituting the fuzzy cluster center and the divided area width in Table 2 into formula (9), the fuzzy membership function for calculating the roller performance degradation as shown in Table 3 can be obtained.
According to the foregoing, the first type of performance degradation index value (with the RMS as the eigenvalues of the vibration data) is obtained by adding the membership value of each roller shaft performance degradation calculation and then averaging; therefore, in combination with Table 3, the formula for calculating the first type of performance degradation index value can be obtained as

$$
\begin{aligned}
T_{\mathrm{X}_{\text {rms }}} & =\frac{\left[\mu_{1}\left(\mathrm{x}_{1}\right)+\mu_{2}\left(\mathrm{x}_{2}\right)+\mu_{3}\left(\mathrm{x}_{3}\right)+\mu_{4}\left(\mathrm{x}_{4}\right)\right]}{4} \\
& =\frac{\left[e^{\left(x_{1}-0.0780\right)^{2} / 0.0010^{2}}+e^{\left(x_{2}-0.0779\right)^{2} / 0.0005^{2}}+e^{\left(x_{3}-0.0771\right)^{2} / 0.0010^{2}}+e^{\left(x_{4}-0.0769\right)^{2} / 0.0002^{2}}\right]}{4}
\end{aligned}
$$

Similarly, the second type of performance degradation index value (with kurtosis as the eigenvalue of the vibration data) is calculated as

$$
\begin{aligned}
T_{K_{v}} & =\frac{\left[\mu_{5}\left(\mathrm{x}_{5}\right)+\mu_{6}\left(\mathrm{x}_{6}\right)+\mu_{7}\left(\mathrm{x}_{7}\right)+\mu_{8}\left(\mathrm{x}_{8}\right)\right]}{4} \\
& =\frac{\left[e^{\left(x_{5}-0.2709\right)^{2} / 0.1001^{2}}+e^{\left(x_{6}-0.2697\right)^{2} / 0.3500^{2}}+e^{\left(x_{7}-0.2702\right)^{2} / 0.7000^{2}}+e^{\left(x_{8}-0.2705\right)^{2} / 0.1150^{2}}\right]}{4}
\end{aligned}
$$

4.3. Calculation and Analysis of Equipment Performance Degradation Indicators. The roller shaft of the equipment shown in Figure 3 was replaced with a new roller shaft. The equipment has been continuously operated for 20 days. During this period, the roller shaft was not lubricated, and 700 sets of roller shaft vibration characteristic data were obtained. Then the equipment roller shaft was replaced with a longer-age roller. The shaft has been continuously operated for 10 days, during which the roller shaft was not lubricated, and 300 sets of roller vibration characteristic data were obtained, so that a total of 1000 sets of vibration characteristic data of each process of the roller shaft were obtained. It should be noted that the guide roller shaft with a long period of time was damaged near the $800^{\text {th }}$ data.
Figure 13 shows the first type of performance degradation index values curve calculated from 1000 sets of data, and Figure 14 shows the second type of performance degradation index values curve.

From Figures 13 and 14, the first and second type of performance degradation index value have been in a relatively stable state before the $700^{\text {th }}$ group of data; however, between 700 and 800 sets of data, the first type of performance degradation index curve began to decline, which indicated that device performance began to decline. After the $800^{\text {th }}$ group, the curves of the first and second types of performance degradation indicators continued to decline, and the changes were more severe, which indicated that the performance degradation of the equipment was more serious. When the 
TABLE 1: Normalized result of characteristic parameters.

\begin{tabular}{|c|c|c|c|c|c|c|c|c|}
\hline \multirow{2}{*}{$\begin{array}{l}\text { Serial } \\
\text { number }\end{array}$} & \multicolumn{2}{|c|}{$\begin{array}{l}\text { Unwinding roller shaft } \\
\text { vibration data }\end{array}$} & \multicolumn{2}{|c|}{$\begin{array}{l}\text { Guide roller shaft } \\
\text { vibration data }\end{array}$} & \multicolumn{2}{|c|}{$\begin{array}{c}\text { Drive roller shaft } \\
\text { vibration data }\end{array}$} & \multicolumn{2}{|c|}{$\begin{array}{l}\text { Winding roller shaft } \\
\text { vibration data }\end{array}$} \\
\hline & RMS & Kurtosis & RMS & Kurtosis & RMS & Kurtosis & RMS & Kurtosis \\
\hline 1 & 0.0741 & 0.2659 & 0.0785 & 0.2651 & 0.0771 & 0.2699 & 0.0750 & 0.2724 \\
\hline 2 & 0.0753 & 0.2763 & 0.0774 & 0.2647 & 0.0793 & 0.2624 & 0.0782 & 0.2759 \\
\hline 3 & 0.0762 & 0.2703 & 0.0790 & 0.2645 & 0.0769 & 0.2680 & 0.0774 & 0.2711 \\
\hline 4 & 0.0787 & 0.2673 & 0.0782 & 0.2742 & 0.0771 & 0.2669 & 0.0783 & 0.2644 \\
\hline 5 & 0.0784 & 0.2716 & 0.0781 & 0.2730 & 0.0774 & 0.2688 & 0.0765 & 0.2653 \\
\hline 6 & 0.0783 & 0.2777 & 0.0768 & 0.2693 & 0.0766 & 0.2736 & 0.0776 & 0.2663 \\
\hline 7 & 0.0786 & 0.2654 & 0.0798 & 0.2755 & 0.0769 & 0.2685 & 0.0757 & 0.2642 \\
\hline 8 & 0.0777 & 0.2810 & 0.0774 & 0.2688 & 0.0773 & 0.2689 & 0.0779 & 0.2726 \\
\hline 9 & 0.0790 & 0.2788 & 0.0784 & 0.2715 & 0.0757 & 0.2688 & 0.0765 & 0.2763 \\
\hline 10 & 0.0757 & 0.2699 & 0.0785 & 0.2702 & 0.0766 & 0.2732 & 0.0763 & 0.2739 \\
\hline 11 & 0.0792 & 0.2694 & 0.0786 & 0.2677 & 0.0774 & 0.2665 & 0.0766 & 0.2682 \\
\hline 12 & 0.0776 & 0.2701 & 0.0776 & 0.2740 & 0.0779 & 0.2717 & 0.0772 & 0.2719 \\
\hline 13 & 0.0774 & 0.2689 & 0.0782 & 0.2647 & 0.0788 & 0.2729 & 0.0776 & 0.2652 \\
\hline 14 & 0.0798 & 0.2642 & 0.0780 & 0.2775 & 0.0775 & 0.2756 & 0.0778 & 0.2758 \\
\hline 15 & 0.0792 & 0.2705 & 0.0764 & 0.2763 & 0.0768 & 0.2670 & 0.0760 & 0.2690 \\
\hline 16 & 0.0786 & 0.2761 & 0.0789 & 0.2704 & 0.0782 & 0.2736 & 0.0760 & 0.2695 \\
\hline 17 & 0.0784 & 0.2670 & 0.0773 & 0.2695 & 0.0767 & 0.2626 & 0.0776 & 0.2716 \\
\hline 18 & 0.0776 & 0.2757 & 0.0782 & 0.2725 & 0.0773 & 0.2734 & 0.0768 & 0.2736 \\
\hline 19 & 0.0774 & 0.2706 & 0.0769 & 0.2722 & 0.0769 & 0.2728 & 0.0760 & 0.2687 \\
\hline 20 & 0.0798 & 0.2763 & 0.0784 & 0.2673 & 0.0748 & 0.2703 & 0.0773 & 0.2717 \\
\hline 21 & 0.0792 & 0.2677 & 0.0785 & 0.2718 & 0.0773 & 0.2782 & 0.0765 & 0.2712 \\
\hline 22 & 0.0776 & 0.2674 & 0.0793 & 0.2664 & 0.0767 & 0.2719 & 0.0762 & 0.2700 \\
\hline 23 & 0.0784 & 0.2659 & 0.0769 & 0.2690 & 0.0777 & 0.2728 & 0.0779 & 0.2673 \\
\hline 24 & 0.0776 & 0.2763 & 0.0766 & 0.2785 & 0.0773 & 0.2653 & 0.0760 & 0.2729 \\
\hline 25 & 0.0778 & 0.2703 & 0.0783 & 0.2724 & 0.0768 & 0.2745 & 0.0768 & 0.2683 \\
\hline 26 & 0.0789 & 0.2673 & 0.0773 & 0.2723 & 0.0749 & 0.2644 & 0.0755 & 0.2721 \\
\hline 27 & 0.0790 & 0.2715 & 0.0774 & 0.2696 & 0.0776 & 0.2719 & 0.0789 & 0.2713 \\
\hline 28 & 0.0793 & 0.2739 & 0.0759 & 0.2697 & 0.0777 & 0.2734 & 0.0772 & 0.2726 \\
\hline 29 & 0.0775 & 0.2711 & 0.0781 & 0.2446 & 0.0785 & 0.2623 & 0.0766 & 0.2692 \\
\hline 30 & 0.0777 & 0.2651 & 0.0786 & 0.2702 & 0.0759 & 0.2764 & 0.0781 & 0.2735 \\
\hline
\end{tabular}

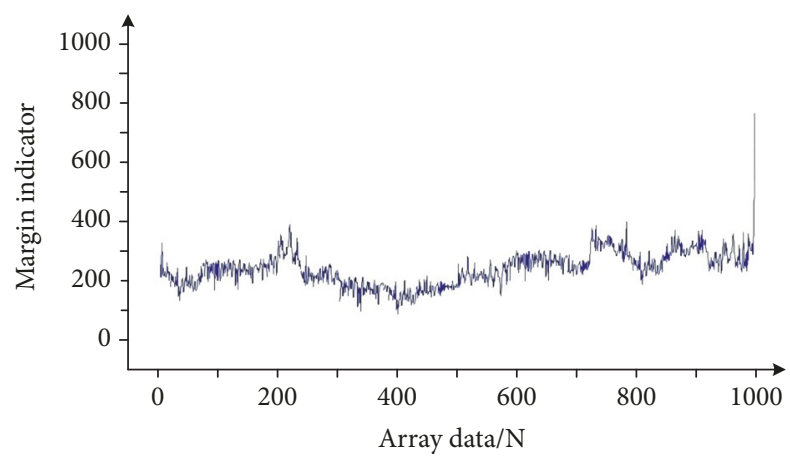

FIgURE 9: Margin indicator.

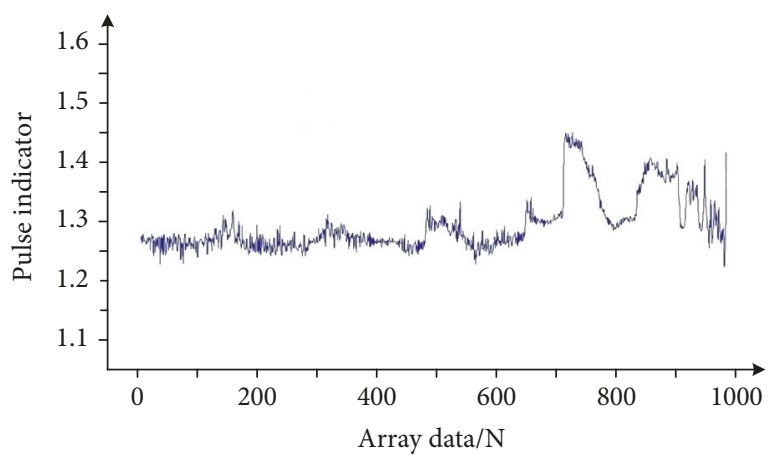

Figure 10: Pulse indicator. data was collected to 980 groups, the roller shafts with a long period of time were too long, resulting in mechanical fatigue, which caused the roller shaft to be damaged, which affected the normal operation. The performance degradation of the device could be reflected intuitively through the graphs in Figures 13 and 14, which means the performance degradation prediction model provides the correct calculation results. 
TABLE 2: Roller shaft vibration data category center position coordinates, division area width.

\begin{tabular}{|c|c|c|c|c|}
\hline \multirow[b]{2}{*}{ Roller shaft type } & \multicolumn{2}{|c|}{ Center position } & \multicolumn{2}{|c|}{ Division area width } \\
\hline & $\begin{array}{c}\mathrm{v}_{\mathrm{ix}_{1}} \\
\text { (eigenvalue is } \\
\text { RMS) }\end{array}$ & $\begin{array}{c}\mathrm{v}_{\mathrm{ix}_{2}} \\
\text { (eigenvalue is } \\
\text { Kurtosis) }\end{array}$ & $\begin{array}{c}\sigma_{\mathrm{ix}_{1}}^{2} \\
\text { (eigenvalue is } \\
\text { RMS) }\end{array}$ & $\begin{array}{c}\sigma_{\mathrm{ix}_{2}}^{2} \\
\text { (eigenvalue is } \\
\text { Kurtosis) }\end{array}$ \\
\hline $\begin{array}{l}\text { Unwinding roller } \\
\text { shaft }\end{array}$ & 0.0780 & 0.2709 & 0.0010 & 0.1001 \\
\hline Guide roller shaft & 0.0779 & 0.2697 & 0.0005 & 0.3500 \\
\hline Drive roller shaft & 0.0771 & 0.2702 & 0.0010 & 0.7000 \\
\hline $\begin{array}{l}\text { Winding roller } \\
\text { shaft }\end{array}$ & 0.0769 & 0.2705 & 0.0002 & 0.1150 \\
\hline
\end{tabular}

TABLE 3: The fuzzy membership function for calculating the roller performance degradation.

\begin{tabular}{lc}
\hline Roller shaft type & Membership function \\
\hline Unwinding roller shaft (eigenvalue is & $\mu_{1}\left(\mathrm{x}_{1}\right)=\mathrm{e}^{\left(\mathrm{x}_{1}-0.0780\right)^{2} / 0.0010^{2}}$ \\
RMS) & $\mu_{2}\left(\mathrm{x}_{2}\right)=\mathrm{e}^{\left(\mathrm{x}_{1}-0.0779\right)^{2} / 0.0005^{2}}$ \\
Guide roller shaft (eigenvalue is RMS) & $\mu_{3}\left(\mathrm{x}_{3}\right)=\mathrm{e}^{\left(\mathrm{x}_{1}-0.0771\right)^{2} / 0.0010^{2}}$ \\
Drive roller shaft (eigenvalue is RMS) & $\mu_{4}\left(\mathrm{x}_{4}\right)=\mathrm{e}^{\left(\mathrm{x}_{1}-0.0769\right)^{2} / 0.0002^{2}}$ \\
Winding roller shaft (eigenvalue is RMS) & $\mu_{5}\left(\mathrm{x}_{5}\right)=\mathrm{e}^{\left(\mathrm{x}_{1}-0.2709\right)^{2} / 0.1001^{2}}$ \\
Unwinding roller shaft (eigenvalue is & $\mu_{6}\left(\mathrm{x}_{6}\right)=\mathrm{e}^{\left(\mathrm{x}_{1}-0.2697\right)^{2} / 0.3500^{2}}$ \\
Kurtosis) & $\mu_{7}\left(\mathrm{x}_{7}\right)=\mathrm{e}^{\left(\mathrm{x}_{1}-0.2702\right)^{2} / 0.7000^{2}}$ \\
Guide roller shaft (eigenvalue is Kurtosis) & $\mu_{8}\left(\mathrm{x}_{8}\right)=\mathrm{e}^{\left(\mathrm{x}_{1}-0.2705\right)^{2} / 0.1150^{2}}$ \\
Drive roller shaft (eigenvalue is Kurtosis) & \\
Winding roller shaft (eigenvalue is & Kurtosis)
\end{tabular}

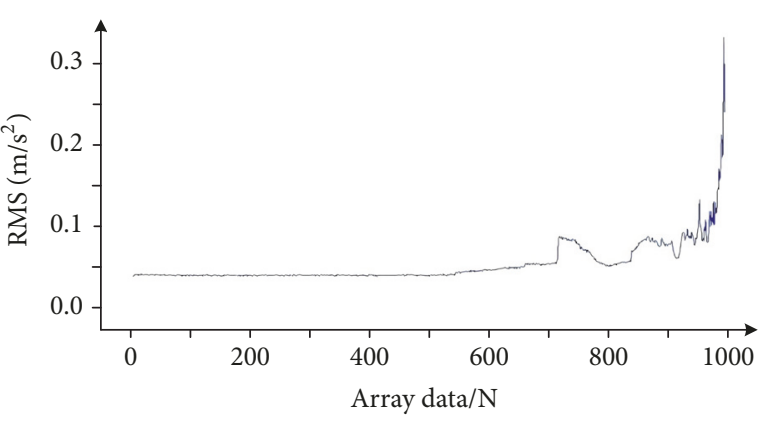

FIGURE 11: RMS value curve.

\section{Conclusion}

The performance degradation of flexible photoelectric film material processing equipment is a nonlinear process. This paper innovatively proposes to use fuzzy membership function to characterize equipment performance degradation and established a model for predicting the performance degradation of flexible material processing equipment based on adaptive fuzzy clustering. Derivation of the category center value of the fuzzy membership function, the parameterization method of the input data partitioning region width, and the algorithm for calculating the performance degradation index are given.

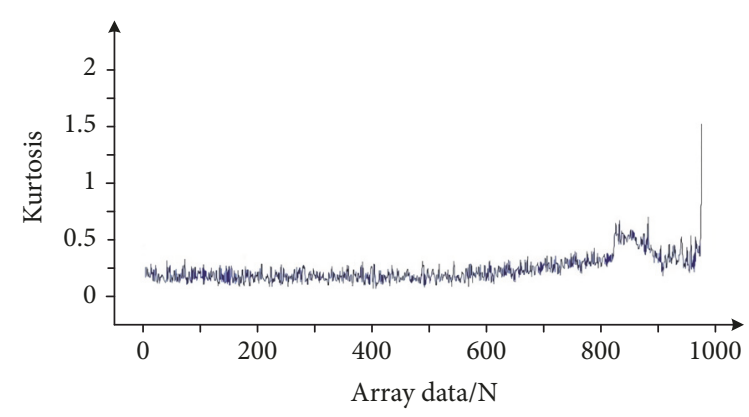

Figure 12: Kurtosis curve.

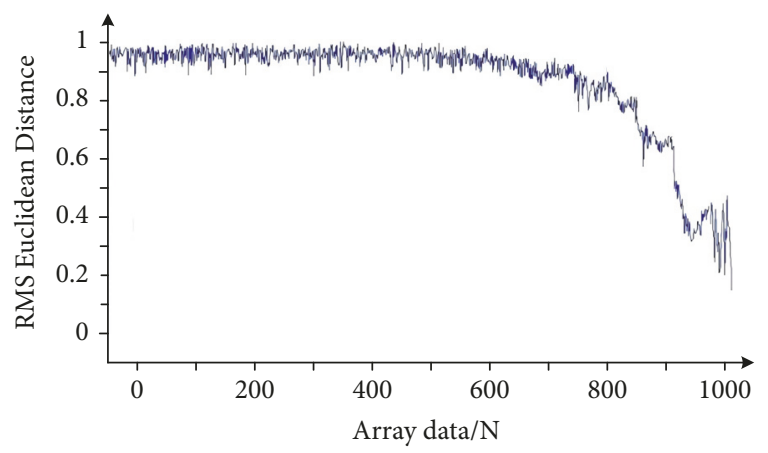

FIgURE 13: The first type of performance degradation index values curve. 


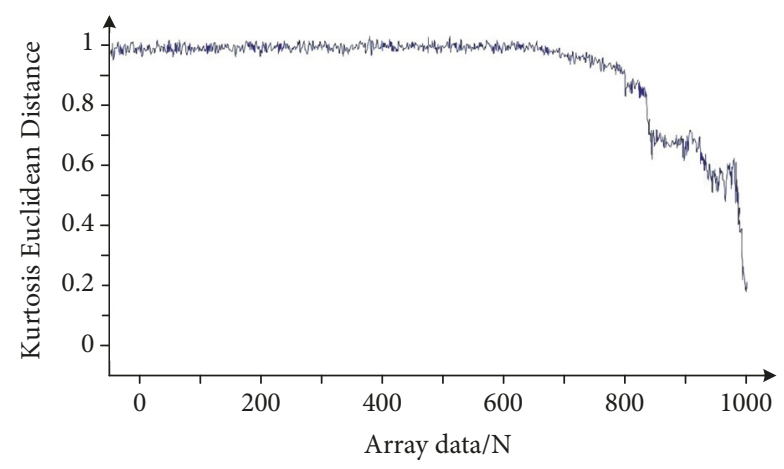

FIGURE 14: The second type of performance degradation index values curve.

Experiments show that the RMS eigenvalues and the kurtosis eigenvalues of the roller vibration data of the processing equipment change very smoothly in the early stage until the end of life reaches a rapid rise phenomenon, which indicates that the RMS eigenvalues and the kurtosis eigenvalues are sensitive to the performance degradation of the roller shaft of the flexible material R2R processing equipment.

The performance degradation prediction model was verified by 1000 sets of characteristic data obtained from the accelerated life test of the equipment. The results show that the performance values of the first and second types of performance degradation indicators are always stable before the $700^{\text {th }}$ data. After the $800^{\text {th }}$ data, the curve of the performance degradation index value continued to decrease. In the $980^{\text {th }}$ data group, the performance of the performance index curve is close to zero due to the damage of the long-lasting roller shafts. This shows the correctness of the performance degradation model calculation model proposed in this paper.

\section{Data Availability}

The data used to support the findings of this study are available from the corresponding author upon request.

\section{Conflicts of Interest}

The authors declared no potential conflicts of interest with respect to the research, authorship, and/or publication of this article.

\section{Acknowledgments}

The authors disclosed receipt of the following financial support for the research, authorship, and/or publication of this article. This work was supported in part by the National Natural Science Foundation of China under Grant No. 51675109, Natural Science Foundation of Guangdong Province, China, under Grant No. 2017A030313308, Provincial Science and Technology Plan Project of Guangdong Province, China, under Grant No. 2016B010124002 and No. 2015B010133004, and in part by the Provincial Science and technology plan of Guangdong Province, China, under Grant
No. 2017B010117011. This work is partially supported by Foshan Science and Technology Innovation Team project in 2015 (No. 2015IT100102).

\section{References}

[1] Y. Deng, X. Liu, Z. Zheng, Q. Zhang, and L. Wu, "A new active contour modeling method for processing-path extraction of flexible material," Optik - International Journal for Light and Electron Optics, vol. 127, no. 13, pp. 5422-5429, 2016.

[2] F. Wu, T. Wang, and J. Lee, "An online adaptive condition-based maintenance method for mechanical systems," Mechanical Systems and Signal Processing, vol. 24, no. 8, pp. 2985-2995, 2010.

[3] H. Yu, F. Khan, and V. Garaniya, "Risk-based fault detection using Self-Organizing Map," Reliability Engineering \& System Safety, vol. 139, pp. 82-96, 2015.

[4] Y. Deng, N. Zhou, X. Liu, and Q. Lu, "Research on Fault Diagnosis of Flexible Material R2R Manufacturing System Based on Quality Control Chart and SoV," Mathematical Problems in Engineering, vol. 2018, Article ID 6350380, 8 pages, 2018.

[5] Y. Deng, Q. Lu, K. Yao, and N. Zhou, "Study on phosphor powder precipitation model in flexible material manufacturing process based on neuro-fuzzy network," Optik - International Journal for Light and Electron Optics, vol. 168, pp. 563-576, 2018.

[6] Y.-H. Deng and G.-X. Liu, "ATS-FNN-based modeling and simulation for compensation prediction of FWP machining deformation," Journal of South China University of Technology (Natural Science Edition), vol. 40, no. 3, pp. 137-142, 2012.

[7] K. H. Memon and D.-H. Lee, "Generalised kernel weighted fuzzy C-means clustering algorithm with local information," Fuzzy Sets and Systems, vol. 340, pp. 91-108, 2018.

[8] T. Gao, A. Li, and F. Meng, "Research on data stream clustering based on fcm algorithm1," Procedia Computer Science, vol. 122, pp. 595-602, 2017.

[9] C. Hai-peng, S. Xuan-Jing, L. Ying-da, and L. Jian-Wu, "A novel automatic fuzzy clustering algorithm based on soft partition and membership information," Neurocomputing, vol. 236, pp. 104-112, 2017.

[10] L. Jie, W. Liu, Z. Sun, and S. Teng, "Hybrid fuzzy clustering methods based on improved self-adaptive cellular genetic algorithm and optimal-selection-based fuzzy c-means," Neurocomputing, vol. 249, pp. 140-156, 2017.

[11] T. Shuhua, W. Hua, and H. Rongjing, "Residual life assessment of slewing bearing based on multivariate eigenvalues fusion and support vector regression," Journal of Nanjing Tech University (Natural Science Edition), vol. 38, no. 3, pp. 50-57, 2016.

[12] M.-S. Xiao, Z.-C. Wen, J.-W. Zhang, and X.-F. Wang, "An FCM clustering algorithm with improved membership function," Kongzhi yu Juece/Control and Decision, vol. 30, no. 12, pp. 22702274, 2015.

[13] S. J. Narayanan, I. Paramasivam, R. B. Bhatt, and M. Khalid, "A study on the approximation of clustered data to parameterized family of fuzzy membership functions for the induction of fuzzy decision trees," Cybernetics and Information Technologies, vol. 15, no. 2, pp. 75-96, 2015.

[14] F. Di Martino and S. Sessa, "Extended fuzzy C-means hotspot detection method for large and very large event datasets," Information Sciences, vol. 441, pp. 198-215, 2018. 


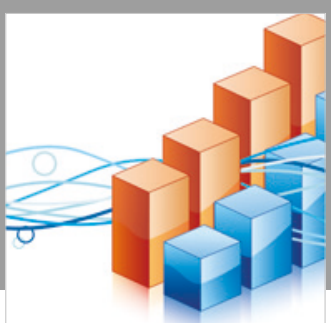

Advances in

Operations Research

\section{-n-m}
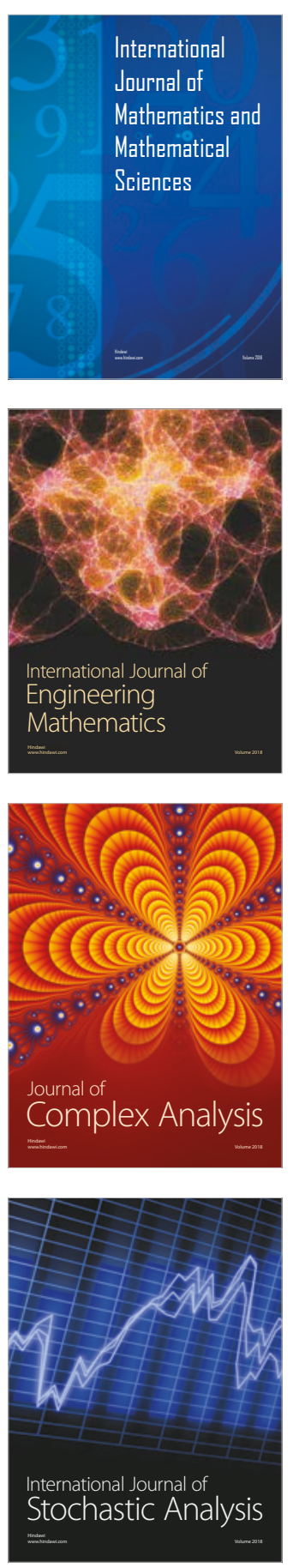
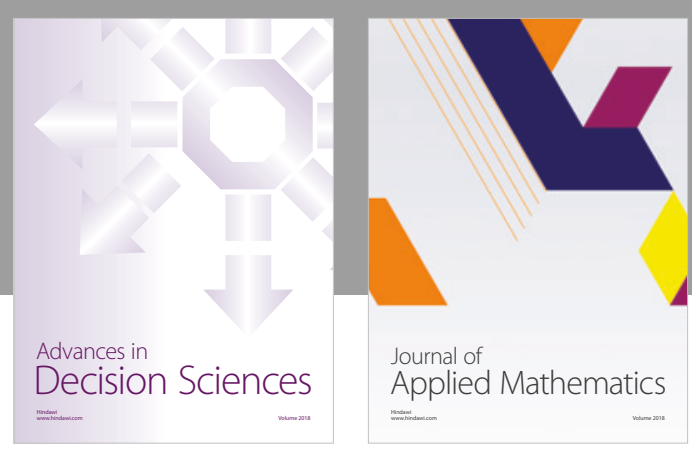

Journal of

Applied Mathematics
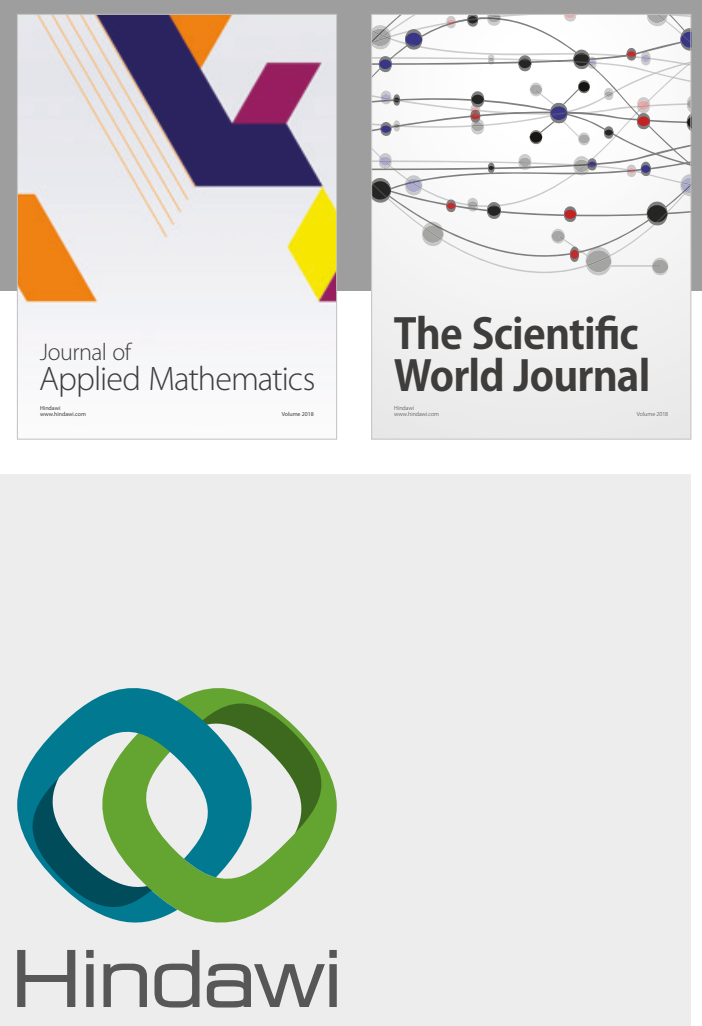

Submit your manuscripts at

www.hindawi.com

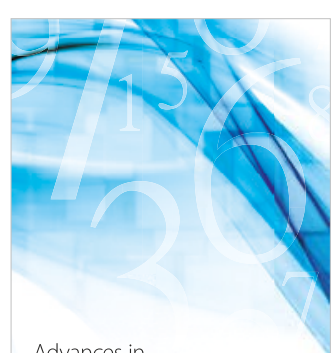

Advances in
Numerical Analysis
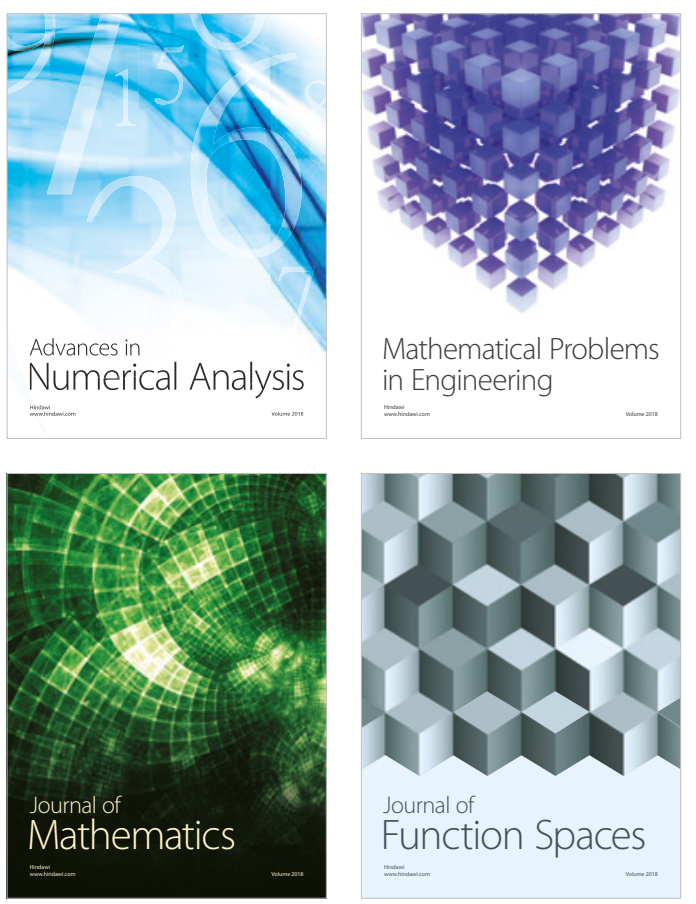

Mathematical Problems in Engineering

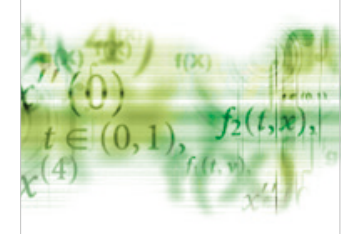

International Journal of

Differential Equations

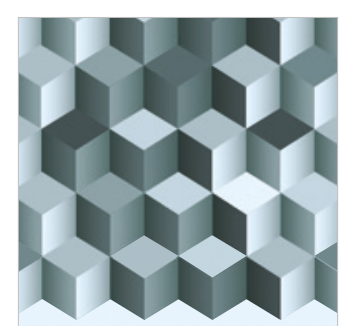

Journal of

Function Spaces
The Scientific

World Journal

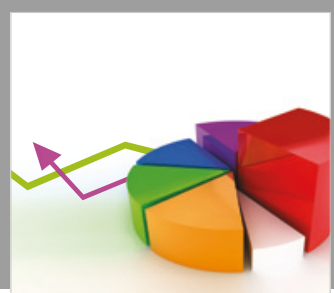

Journal of

Probability and Statistics
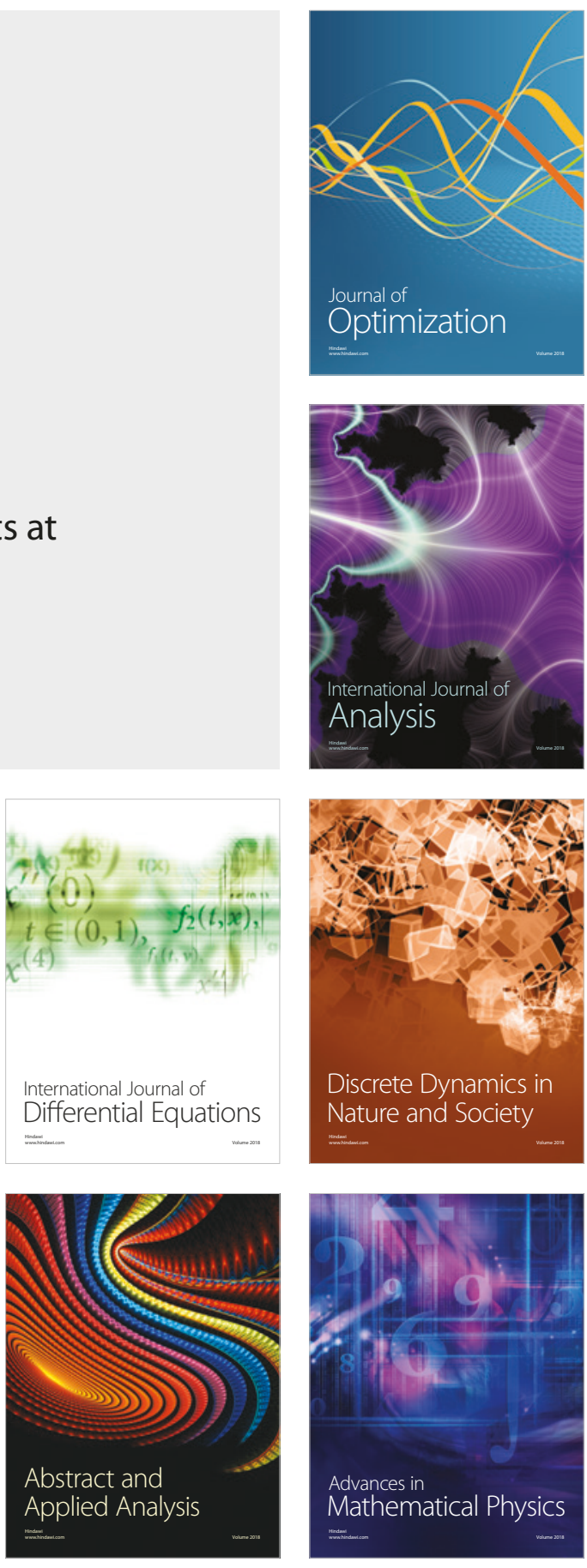